\title{
Thinkpiece
}

\section{Would lifting the income contribution cap to NEST and the ban on transfers- in be contrary to EU state aid rules?}

Received (in revised form): 6th November 2012

\begin{abstract}
Dr Andy Tarrant
is senior parliamentary assistant to Gregg McClymont MP, Labour's Shadow Pension Minister. He is an EU Competition lawyer by training and was previously Head of Global Government and Regulatory Affairs at BT Global Services; Regulatory Affairs Director at the European Competitive Telecommunications Association; Senior Competition Lawyer, British Telecommunications PLC; and Head of the International Section, OFTEL. He qualified at Herbert Smith solicitors.
\end{abstract}

ABSTRACT This analysis is a contribution to a debate opened by the Department of Work and Pensions Select Committee. On 15 March 2012 it published its report, Automatic enrolment in workplace pensions and the National Employment Savings Trust, HC 1494. In the report, parliamentarians from the three major parties recommended unanimously that the income contribution cap and the ban on transfers-in to NEST be removed as long as this is consistent with EU state aid rules. In light of this statement, I have examined whether the removal of these restrictions would be consistent with EU state aid rules or not. In short, my view is that removal of these particular restrictions is likely to be consistent with EU state aid rules. I have heard the view that an unfettered NEST might dominate the pensions market. I set out why the characteristics of demand and supply, including the nature of the Public Service Obligation imposed on NEST, make this implausible. Given the oft-expressed concern that the UK 'gold-plates' EU requirements, it may be useful to underline that the burden of proof faced by the United Kingdom in lifting the restrictions is not to prove that this is necessary beyond any reasonable doubt. Instead, the obligation on a Member State is to show that such a step is a reasonable step in the light of the information that is currently available. The evidence available today is that the restrictions are impeding NEST's ability to act as a service of general and economic interest. Given the importance of NEST in ensuring that low and moderately earning employees save into pensions, in a context where only 33 per cent of private sector employees are saving into an occupational pension, it would not be in the public interest for the UK authorities to unilaterally adopt a higher standard of proof and to choose to wait until they can prove beyond any reasonable doubt that the restrictions damage NEST's ability to meet its public service obligation. By that time, many employees would already have been signed up to pension schemes that are not in their best interests and NEST may struggle to achieve the scale necessary to minimise its costs for members. This would not be a recipe for ensuring a low opt-out rate and the success of the policy of auto-enrolment. EU law gives Member States wide discretion to define Services of General Interest ('SGEI'). A no-frills, universal-enrolment NEST service would still be a properly defined SGEI even if the current restrictions are lifted. If the start-up support given to NEST is proportionate - and there are mechanisms in place to ensure that it will be - there is no reason to assume that merely lifting the current restrictions will infringe EU state aid law.

Pensions (2012) 17, 191-207. doi:10.1057/pm.2012.39

Keywords: NEST; EU state aid; restrictions; auto-enrolment; workplace pensions

Correspondence: Andy Tarrant

E-mail: andrewk.tarrant@parliament.uk 


\section{INTRODUCTION}

The analysis is set out in the following way:

Section 2: Key background information

Section 3: Issues of legal process including the burden of proof on the UK authorities

Section 4: The key legal issues to be resolved:

- Does NEST have the cost basis of a typical 'well-run' undertaking, given the public service obligation ('PSO') it has to deliver?

- Would the revised PSO (that is, without the restrictions) foreclose competition more than is necessary to provide the PSO?

- Would there be any over-compensation of state aid?

Section 5: Concern that DWP has not revisited the assumptions behind their economic modelling

Section 6: Market developments since 2010 have reinforced the need for the restrictions to be lifted

Section 7: Conclusion

\section{BACKGROUND}

\section{Key pieces of background information}

The sub-sections below set out: a short summary of EU state aid law; a short summary of the Commission's original state aid decision; a description of the two restrictions on NEST which the Select Committee recommended should be lifted; a description of NEST's public service obligations; and the nature of the subsidy received by NEST. These comprise the key pieces of background information relevant to the more detailed consideration of the legal issues in Section 4.

\section{EU state aid law}

EU law prohibits aid from the state that distorts or threatens to distort competition by favouring certain undertakings and which effects trade between Member States.

The conditions that must be met for an aid to fall within this prohibition include that it must provide an 'advantage'. An advantage is not considered to exist if the aid provided is compensation for the provision of a public service and is accorded under certain criteria. These criteria were set out in the Altmark case by the European Court of Justice ${ }^{1}$ :

(...) First, the recipient undertaking must actually have public service obligations to discharge and those obligations must be clearly defined (...)

(...) Second, the parameters on the basis of which the compensation is calculated must be established in advance in an objective and transparent manner $(\ldots)$

(...) Third, the compensation cannot exceed what is necessary to cover all or part of the costs incurred in the discharge of the public services obligation, taking into account the relevant receipts and a reasonable profit (...)

(...) Fourth, where the undertaking which is to discharge public service obligations, in a specific case, is not chosen pursuant to a public procurement procedure, which would allow for the selection of the tenderer capable of providing those services at the least cost to the community, the level of compensation needed must be determined on the basis of an analysis of the costs, which a typical undertaking, well run and adequately provided within the same sector would incur, taking into account the receipts and a reasonable profit from discharging the obligations.

Note that even if it did not meet all the Altmark criteria, an aid can nonetheless obtain clearance from the European Commission if the aid is to provide a service of general economic interest ('SGEI') and prohibition of the aid would obstruct the performance of the particular public service assigned to the body. ${ }^{2}$ Lifting the prohibition on an aid must not affect the development of trade between Member States to an extent which would be contrary to the interests of the Union. This was the test under which the subsidy was first cleared by the Commission.

This note takes the view that the issue of the subsidy to NEST would now be assessed under the Altmark criteria and so focuses on that assessment. 


\section{The Commission's 2010 clearance decision}

In 2010, the European Commission

('Commission') held, inter alia, that the aid provided to NEST constituted an 'advantage'.

While the Commission found that (a) the United Kingdom had made no manifest error of assessment in finding that there was a market failure in the provision of pensions to low and medium earners in the United Kingdom, that is, that NEST's service is a genuine public service;

(b) the service is entrusted to NEST by an official act that contains all the elements of the service; and (c) the undertaking is not overcompensated for the provision of the public service, the Commission did find that the aid did not meet the fourth Altmark criterion. This was because NEST was not yet operational and so could not show that it could operate at the level of costs of a typical undertaking. The Commission nonetheless cleared the aid to NEST under Article 106(2) TFEU. This was because the Commission considered that NEST was an SGEI and the aid was proportionate and necessary for it to fulfil its public service obligation. ${ }^{3}$

The finding that NEST was an SGEI was based on the fact that NEST is targeted on low to moderate earners (Commission decision: para 100). The Commission noted the range of measures put in place by the United Kingdom to achieve this objective without commenting on the necessity or otherwise of the full panoply of supporting measures deployed (paras 37-40 4 ). The income contribution cap and the ban on transfers-in comprise just two of the range of supporting measures (see sections 'NEST's public service obligation' and 'The key legal issues' below for a longer discussion of the range of measures). The Act notified to the Commission also contained a mechanism for review and removal of restrictions.

\section{The nature of the income contribution cap ('Cap') and ban on transfers-in ('Transfer Ban')}

The Cap limits the amount any individual can pay into their saving account to NEST in any one year to $£ 4400$ (which includes the contribution from the employer and tax relief from the state as well as the employee's contribution).

The Transfer Ban prevents employers and employees from shifting savings accumulated in historic schemes with other pension providers to NEST, even if the terms and conditions of the former are significantly inferior.

\section{NEST's public service obligation}

NEST's PSO is set out in the Pensions Act 2008 (the 'Act') and in statutory implementation of the Act.

Under the Act, NEST is required to offer a pension saving at 'a minimised cost to anyone requesting it' (s.80(2)(d)) and in a way that 'minimises' burdens on businesses (S.80(2)(b)). NEST is also required to minimise 'any adverse effects on qualifying schemes, and members and future members of those schemes' (s.80(2)(c)).

NEST is also obliged to offer a standard price with no price differentiation between members. ${ }^{5}$ This is to prevent lower income workers being discriminated against in terms of price, discouraging participation in the scheme.

The Cap and the Transfer Ban can be seen as qualifications on the obligation in $\mathrm{S} .80(2)(\mathrm{d})$ to offer pension saving at 'a minimised cost to anyone requesting it'. Individuals cannot request this service with respect to past savings and they cannot save above a threshold in any given year.

The requirement to offer service to anyone requesting it necessarily means that NEST must provide services to some members that will be loss-making and that it needs to be built on a scale which will enable it to serve anticipated maximum membership at the outset. It cannot control cost or risk by controlling its uptake of members through restricting access.

Different elements of the PSO obligation can be in tension. The UK government should exercise its discretion in balancing the objectives in a reasonable way to achieve the overall objectives of the policy. The view taken in this note is that the Cap and the Transfer-Ban now give too great a priority to $\mathrm{s} .80(2)$ (c)

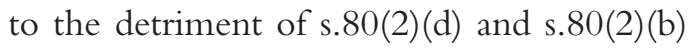
of the Act. 


\section{What is the aid?}

According to the Commission decision, NEST will not be able to remunerate the borrowed funds necessary to set up and cover the difference between costs and revenues at a market rate for between 20 and 27 years (para 87). The state aid provided is intended to compensate for this gap by providing interest relief in the form of a loan to meet the difference between the commercial rate and the rate at which the state can borrow.

\section{What would be the effect of lifting the Transfer Ban and the Cap on the amount of aid?}

Lifting the ban on transfers-in would clearly not give rise to any increase in the aid at all. It could only have the effect of increasing the revenues received by NEST. As the Commission notes at paras 124 and 148, the UK government has put in place mechanisms to recuperate the loan more rapidly and ensure there is no over-compensation if NEST's revenues turn out to be higher than predicted.

The effect of lifting the Cap on contributions is likely to work slightly differently. In so far as it leads to greater membership than predicted, it would lead to a higher initial subsidy. ${ }^{6}$ However, due to the higher revenue stream this would be likely to be more than balanced by a reduction in the number of years necessary to pay back the loan. And, as above, the UK government has in place mechanisms to claw-back any over-compensation.

\section{PROCESS ISSUES}

\section{Is there a requirement to notify the Commission if the UK government decides to lift the Cap and the Transfer Ban?}

There is no legal requirement to notify a subsidy if it does not comprise state aid for the purposes of EU Law. A subsidy would not comprise state aid if it met the criteria set out by the European Court of Justice in the Altmark case. ${ }^{1}$ The Commission found in its 2010 decision that the subsidy to NEST met three out of the four criteria set out in Altmark (see section 'EU State Aid Law' above). The ground which could not be proven at the time was the requirement to show that NEST's operating costs would likely to be those of a 'typical undertaking' tasked to meet the services its public service obligation requires. This was because NEST was not yet operational at the time. NEST is now operational and would now appear to meet this fourth criterion. ${ }^{7}$

The government can notify the Commission to obtain clearance for lifting the Cap and the Transfer Ban. Notifying the Commission would remove any threat of domestic UK litigation against the UK government on state aid grounds. ${ }^{8}$ If the Commission decided that the subsidy to NEST was no longer State aid (or that removal of restrictions on NEST did not render any existing State aid incompatible with the internal market), that decision could not be challenged before the English courts.

\section{What standard of proof does the UK government need to meet as regards justifications for redesigning the PSO?}

The UK government needs to put forward a reasonable prima facie case based on the evidence which can be adduced today. The UK government does not need to prove beyond all reasonable doubt that lifting the restrictions is and will always be necessary.

The European General Court has stated that the Commission's role should be understood as follows:

As regards, in particular, the extent of the Commission's remit, the Commission cannot take the place of the Member States in the exercise of the wide discretion which the latter enjoys. Thus, in assessing whether the measure in question is necessary, the Commission has no power to ascertain, on the basis of the available data, whether the market might actually develop in a certain way and whether the application of the regulatory instruments envisaged by the notified system will thereby become indispensable, at a given moment, to ensure the achievement of the mission involving the provision of a service of general economic interest in question. In effect, the review of necessity does not require that the Commission be convinced that the Member State, in the light of present or future conditions, cannot abandon the notified measures, but is limited to ascertaining whether there has been a manifest 
error in the exercise of the wide discretion of the Member State as regards the way of ensuring that the mission involving the provision of a service of general economic interest may be achieved under economically acceptable conditions. ${ }^{9}$

\section{How long should the process of notification take?}

A Member State with a good case and that wished the Commission to conclude with the initial investigation would engage the Commission in prenotification talks. Should the investigation go to second stage the Commission could take between six months and two years. In practice, the rapidity of the exercise will depend on how well the Member State has prepared its case and the extent to which the Member States signals to the Commission that the issue is a political priority.

In this particular case, the Commission has already made a decision with respect to NEST.

A new notification does not represent an entirely new set of issues with which officials would have to familiarize themselves. There are three substantive issues to be resolved:

(i) Does NEST have the cost basis of a typical 'well-run' undertaking?

(ii) Would the revised PSO (that is, without the two restrictions under discussion) foreclose competition more than is necessary to provide the PSO and thereby mean that the United Kingdom is committing a 'manifest error' ${ }^{10}$ in conducting what would effectively be a revision of the definition of the public service obligation?

(iii) Would there be any over-compensation through state aid?

These three issues could be resolved within a reasonable time-frame if it was a Government priority.

\section{THE KEY LEGAL ISSUES}

\section{Does NEST have the cost base of a typical 'well-run' undertaking, given the PSO it has to deliver?}

The Commission found in its decision that it could not yet be said that NEST met the fourth
Altmark criteria as it was not yet operational (para 104). NEST is now operational.

NEST's costs are published in its Annual Report and Accounts. ${ }^{11}$ The information is comprehensive. They reveal, inter alia, that it has 184 staff with a median salary of $\$ 54000$ and a chief executive who is paid a basic salary of $£ 232500$. Its premises are modest, located outside the more expensive locations in which most financial institutions are to be found and therefore likely to be comparatively low-cost. Many of the component parts of NEST's services including scheme administration, IT and investment are provided under contract after competitive tendering processes. It would be for the UK government to provide the appropriate comparators to the Commission - but these are all indicators of a cost base that is likely to compare favourably with the typical 'well-run' private undertaking in the sector.

Note that in assessing the quality of its cost profile, the cost of delivering the public service obligations must also be taken into account, ${ }^{12}$ in particular the need to be able to operate at scale.

\section{Would the revised PSO (that is, without the restrictions) foreclose competition more than is necessary to provide the PSO?}

\section{Do the current restrictions frustrate NEST from delivering on the PSO?}

I set out in the sub-sections below why the Cap and the ban on transfers-in frustrate delivery of the PSO. However, as a preliminary point it is worth noting how the Commission defined the PSO. In its NEST decision, the Commission found that the market failure that would be addressed by NEST was that 'after automatic enrolment, many employers and workers would remain unprofitable to providers and be excluded from low cost saving' (Commission Decision, para 22). This formulation by the Commission is very apposite. It captures the important point that market failure occurs not only where employers and employees are excluded altogether by the workings of the market, but also where they could be excluded from low cost saving. 
Private providers may well be willing to include some employers and employees that would otherwise be unprofitable by raising the price such that saving could not be categorised as low cost. In practice, of course, this would of course likely lead to very high levels of opt-out on the part of savers.

The Cap It is said that the Cap is intended to ensure that NEST remains focused on low and medium earners. However, the Cap is unnecessary for obliging NEST to pursue this objective. The PSO requirement to serve all means that NEST already has in place a legal obligation to focus on low and medium earners. The NEST product has been designed to that end and its price and other product features mean that it will be more attractive to that demography (and less attractive to others: see the next section).

The arbitrary nature of a monetary limit in the Cap also serves to undermine the PSO. It does not take into account the age at which someone begins a pension. If the age of the individual is say 45 and starting a pension, then they need to be paying in a much higher percentage of their salary in order to achieve a reasonable income in retirement compared with a 25 -year old. It would typically be reckoned that a 45-year old should be saving 25 per cent of their salary not 8 per cent. The Cap prevents NEST from delivering appropriate service to all its members or potential members. The Pensions Management Institute told the DWP Select Committee that as a consequence the Cap would 'frustrate the overall objective of promoting adequate levels of retirement saving. ${ }^{13}$

It also excludes any employers who want to make a higher contribution rate for their employees. Companies that currently contribute into defined benefit schemes in the United Kingdom on average contribute 16.5 per cent of the employee's salary. ${ }^{14}$ Many of these companies are closing their defined benefit schemes and putting new employees into defined contribution schemes. They may wish to contribute more than the minimum 3 per cent employer contribution required under auto-enrolment.
Is the Cap necessary to ensure that NEST does not replace private providers' services to higher earners? The Cap might be a proportionate means of achieving this if there were (a) always separate demand for occupational pensions for higher earners; (b) there were no damaging consequences for low to medium earners as a consequence of the existence of the Cap; and (c) replacement of private providers as a class was a plausible concern.

However, and critically, demand-side factors mean that for most employers there is not a severable market of low and medium earners and high earners. Most employers will employ a mix of low, medium and higher earners. ${ }^{15}$ By excluding NEST altogether from providing pensions to employers with employees from across the income spectrum, the Cap damages NEST's ability to meet the identified market failure.

It does so in two respects:

(i) It means that many businesses will not consider NEST and may enrol their lower paid workers in schemes that do not meet the price and objective quality standards that would be most appropriate for those employees - leading to a combination of detriment and likely higher rates of opt-out; and

(ii) Pensions is an industry subject to economies of scale. By being excluded from large segments of the market, the cost of participation in NEST will be driven up for those employees who do belong to it - this is contrary to the PSO requirement to 'minimise' cost.

For the reasons discussed in section 'Would lifting the Cap allow NEST to drive private providers out of the pensions market?', it is implausible that in the absence of this measure that NEST will replace private providers as a class. ${ }^{16}$ NEST is unlikely ever to be of interest to firms with high proportions of higher earners. The two groups of businesses where lifting the restrictions would probably allow it to compete would be (a) those small and medium enterprises where there are relatively few higher earners and the latter's salaries are relatively low; and (b) in 
those large enterprises where the most senior employees are in a distinct pension scheme and the business' employment profile otherwise looks like that set out in (a): a mix of higher and lower earners.

The purpose of state aid is not to replace commercial providers who are already providing services consistent with the public interest as defined by the State. ${ }^{17}$ It is, however, entirely within the scope of the Member State's discretion to decide that a service of general economic interest is necessary to ensure a service which private undertakings will not provide to the same 'extent or under the same conditions' as the State considers to be in the public interest. ${ }^{18}$

The Cap also imposes additional 'policing' costs on NEST. ${ }^{19}$

The Transfer Ban It is difficult to see how the Transfer-Ban serves a purpose of ensuring that NEST remains focused on low and medium earners. It prevents employers from selecting a pension scheme for accumulated savings for individuals within the existing Cap where that pension scheme (NEST) is legally required by the PSO to meet the necessary objective standards of decent pension provision for low and medium earners.

Even worse, many insurance companies in the United Kingdom deploy a practice known as 'active member discounts' ('AMD's) (higher quality providers tend to decline to offer the facility on the basis that it is unethical). An employer that shifted to NEST could be exposing their existing workforce to such charges due to the ban on transfers-in, thereby undermining the objectives of the PSO. AMD terms permit additional non-costbased charges to be attached to the savings of an individual if they leave a pension scheme and become a 'passive' (that is, non-contributing) member. These additional charges can be high.

NEST is designed to increase the number of employees that will be covered by a basic pension scheme. Allowing transfers-in to NEST (in the same way as is permitted for the rest of the industry) could encourage private pension providers to maintain and expand their customer base by improving the quality of their service with respect to accumulated savings. It may be that some individual providers would be unable or unwilling to do so, and by that failure would become less competitive. However, as discussed below, in the next section, there is extensive scope for market consolidation in this sector and for private pension providers to improve their services. Member States are certainly not obliged under EU law to keep in place mechanisms such as a Transfer Ban which frustrate such beneficial market development. Given the above, the Transfer Ban is unnecessary to comply with EU law.

\section{Would lifting the Cap allow NEST to drive private providers out of the pensions market?}

The nature of the product which NEST offers means that lifting the Cap would not allow NEST to dominate the pensions market These characteristics include price, the simple nature of the NEST product, NEST's non-use of financial advisers and NEST's inability to cross-sell.

These characteristics explain why some private pension providers have no objection to the income Cap being lifted from NEST.

The CEO of Hargreaves Lansdown has, for example, observed: '... Hargreaves Lansdown believes that the pensions industry should always look to the best interests of investors. The special restrictions imposed on NEST simply make pensions more complicated and for this reason we support the proposal that the restrictions should be lifted. NEST will serve a useful purpose as an underpin for auto-enrolment, and any commercial company that fears its own offering is not competitive should look to the quality of their own product or service, not seek to restrict NEST', ${ }^{20}$

Price of NEST services NEST cannot price discriminate, ${ }^{5}$ it charges a single fixed price of 0.3 per cent annual management charge ('AMC') and a 1.8 per cent charge on each annual contribution from each member. Over 20 years this should lead to an average annual charge of 0.5 per cent. Private providers, on the other hand, are free to price discriminate and do so. ${ }^{21}$ Large companies 
and companies with many higher paid employees will generate higher absolute fees and this allows providers to lower the AMC for contributing members. The Association of British Insurers note that 800000 members in pre-existing schemes already pay less than 0.5 per cent in the annual management charge. A total of 1700 schemes have charges below 0.3 per cent, of these 95 per cent have less than 500 members and 62 per cent less than 50 members. ${ }^{22}$ This of course is feasible where there are low participation rates for low/ moderate earners.

NEST must price to cover loss-making customers, the customers NEST's competitors will avoid. The Commission's decision on state aid rightly noted that NEST was not a vehicle for inter-generational solidarity; however, it should perhaps have made clearer that NEST does require a degree of intra-generational solidarity. The loan from the UK government provides for start-up funding; it does not avoid the need for this implicit ongoing cross-subsidisation within cohorts of savers.

Simple product Based on research as to what would appeal to low and moderate earners, ${ }^{23}$ NEST offers a very basic set of funds in which to save: offering a closed list of six possibilities to employers and employees. This contrasts to the much more extensive range normally offered by private providers to employers. Providers of GPPs typically offer anything from 40 to 500 funds to members, with 150 being typical across all providers $^{24}$ - employers often then choosing a sub-set to offer to employees. This choice will usually include in-house funds but also external funds with high brand recognition. People who wish to exercise choice as to the underlying funds in which they invest are less likely to be attracted to NEST. A typical independent financial advisor notes: '... moderate to high earners or employees looking for a greater degree of choice [our emphasis] and higher contribution levels may not find NEST the most appealing solution'.25

Employers may also want more bespoke and differentiated pension arrangements than those which NEST can provide. Examples would include: (i) demand for SIPPS ${ }^{26}$ and other investment funds/vehicles particularly for higher paid staff; (ii) voluntary bonus substitution by the higher paid for employer lump sum pension contribution arrangements; (iii) ability to top up basic pension savings through a mix of corporate branded savings products such as corporate ISAs; (iv) differentiated company pension arrangements depending on length of service and income/status level; (v) additional provisions in the company scheme such as ill health and death benefits; (vi) high levels of advice built into the package.

Straight-forward product NEST charges an AMC of 0.3 per cent and a charge of 1.8 per cent on each year's contribution. The agreement between NEST and the funds in which it invests limits deductions for transaction-related services from the aggregate funds (an arrangement described in industry parlance as 'clean funds'). There are no charges when an individual changes employer. There are no penalty charges if an individual ceases to contribute. At retirement, an individual saving in NEST is presented with a decision tree which will lead them in the direction of the correct kind of annuity for their circumstances. A panel of annuity providers are obliged to make offers to the individual. The latter are required to meet quality criteria set by NEST to participate. NEST does not provide annuities itself.

This is very different from the practices deployed by many private sector operators in the United Kingdom. Additional costs and charges can be used by private providers to allow them to lower the headline annual management charges. The latter is the figure on which employers and employees are encouraged to focus.

Additional charges can occur as follows:

- The annual management charge may not represent the sum of annual management charges. The underlying funds in which the scheme invests can have separate annual management charges. These should be declared in the Total Expenses Ratio. However, pension providers have a poor record in making these known. ${ }^{27}$

- Consultancy charges on set-up taken from employers contribution. ${ }^{28}$ 
- There may be a separate administration fee; this should also be declared as part of the Total Expenses Ratio.

- 'Allocation rate' - less than 100 per cent of the savings may be invested and a proportion retained by the provider.

- Churning portfolios leads to transaction costs that are not made transparent. Pension providers claim that this is of no benefit since it is only a cost. However, there may be soft commission's available to pension schemes from brokers and custodians which do benefit the providers. It may be the case that bid-offer spreads are not always the most 'efficient'. ${ }^{29}$

- Stock-lending risks charged to the fund while benefits go to the provider. ${ }^{30}$

- Exit fees may be charged to individuals who exit the pension scheme. ${ }^{31}$

- Penalty charges may be imposed on individuals who are not actively contributing to the scheme. ${ }^{32}$

- In the annuity purchasing phase, most individuals purchase from their vertically integrated provider. Despite some claims to the contrary, ${ }^{33}$ inertia is effectively being harnessed to deliver individuals significantly worse annuities than they would achieve on the open market (and thus greater profit for the providers). ${ }^{34}$

- Non-cost-based bid-offer spreads may occur on transfer between pension schemes.

\section{Extensive consultation requirements Part of NEST's}

$\mathrm{PSO}$ requires it to operate with trustees, maintain employer and employee panels, consult widely with members on investment choices and keep members updated about their savings. Its activities here represent a best practice which some private providers may not always observe as closely. Operating on this basis is more costly than not doing so.

NEST is a non-profit organisation NEST is a nonprofit organisation. It cannot use retained profit to compete.

Non-use of independent financial advisers NEST does not have a distribution agreement with any independent financial advisers ('IFA's). This is in order to reduce the costs of participation. As a consequence, NEST's product has been designed to allow employers to engage directly online with ease and so to avoid the use of intermediaries. However, historically, employers have usually sought pension schemes via independent financial advisers or employee benefit consultants who provide a recommended short-list. In 2011, the ABI estimated that 89 per cent of pension schemes were set up this way. ${ }^{35}$ Proposed new rule changes have banned ongoing commissions, so financial advisers will have to recoup their charges as up-front fees. Employers continue to have the option of allowing them to be deducted up front from contributions into the scheme (if the provider agrees). The logical consequence is that many IFAs will not recommend NEST as NEST will not allow such deductions to be made due to consumer detriment. A number of its private sector competitors have agreed with IFAs to permit deductions.

No access to cross-selling NEST only provides pensions whereas almost all of its competitors sell other investment products and some may also sell other forms of insurance. ${ }^{36}$ In particular, most of NEST's competitors sell annuities for which price competition is currently non-existent for the bulk of customers. NEST cannot cover its costs of dealing with employers and employees over a range of products.

Fragmentation of the market: the industry context in which NEST provides its product The fragmented nature of the market in the United Kingdom means that there is significant scope for private operators to achieve economies of scale through internal reorganisation and through market consolidation. If NEST were to begin to gain scale, other operators can do this also. It is worth noting that NEST currently has 800 members while the largest private provider probably has close to 2 million.

The benefits of scale have not been available to most purchasers. DC pensions have traditionally been provided to either the individual or to all the employees of a single firm. This has meant that the economies of scale potentially available to savers have only been achieved by the largest 
individual employers. The National Association of Pension Funds ('NAPF') have found that AMCs of 0.2 per cent are available to employers with 10000 or more employees.

There is currently a great deal of scope for consolidation. There are currently between 1 and 2 million workers in 46540 trust-based and hybrid DC schemes in the United Kingdom. ${ }^{37}$ In all, 95.9 per cent are in schemes with less than 100 people. ${ }^{38}$ The NAPF estimates that there are 134000 GPP and stakeholder schemes with 3 million people ${ }^{39}$ and there are a further 3 million people with individual pensions. ${ }^{40}$ (In addition, there are 6850 defined benefit schemes with about a million active members which are expected to be replaced in the near future by DC schemes.)

However, the use of the word scheme does not imply that each one is served by a different pension provider. Many will be served by the same underlying provider. In other words, some of the economies of scale available in the market have already been realised by suppliers. While there are a very large number of providers, a much more limited number have already gained very significant market shares. For example, figures produced by the ABI for the GPP and corporate stakeholder market show that in 2010 that Legal \& General managed 26 per cent of all insurer-administered pension funds and five companies accounted for 66 per cent of all insurer-administered pensions funds in the year. ${ }^{41}$

Providers like Legal and General are also responding to employers and their subsidiaries or groups of employers that are demanding that they can purchase collectively to achieve the benefit of scale. These collective schemes for multiple employers are called 'master trusts'. ${ }^{42}$ It is likely that their renaissance is partly a reaction on the part of providers to market entry from NEST. ${ }^{43}$

Nonetheless, there is scope for much further consolidation among the private operators and separately for the benefits of the economies of scale to be passed onto savers. There is no objective necessity for there to be large pricing differences between different size companies for contract-based defined contribution schemes. Providers choose to organise on this basis because it allows them to price discriminate and to benefit from information asymmetries against less resourced employers. ${ }^{44}$

Currently, lack of transparency makes it impossible to say with any certainty how high the true costs of pension saving are in the United Kingdom. ${ }^{45}$ Much of the industry fails to comply with existing disclosure requirements ${ }^{46}$ and it is not yet clear whether there will be industry agreement to disclose all costs and charges in a clear and simple form to both employers and employees. ${ }^{47}$ Nonetheless, modelling by the NAPF suggests that consolidation down to a smaller number of competitors, even if that number remained as high as 40 large competitors (which the National Association of Pension Funds call 'Super Trusts'), would deliver considerable costs savings to savers (Figure 1):

Modelling undertaken for the NAPF shows that Super Trusts could be offered at low cost, at around 40bpts, low compared to today's charges which show that the average charges in trust-based schemes are 1 per cent and that 45 per cent of contract-based schemes had charges in excess of 1 per cent. Moreover the advantages of strong governance could ensure that costs remained low and fell further as assets under management grow.

The benefits of lower cost for the consumer would be considerable: someone saving in a large employer's occupational scheme with a 0.3 per cent annual management charge (AMC) could have a pension worth 30 per cent more than someone facing a 1.5 per cent AMC..$^{48}$

\section{Evidence of the effect on NEST of the Cap}

Mark Jaffray of Hymans Robertson, a firm of UK consulting actuaries, said that '... We have discussed using NEST as an auto-enrolment solution with several clients and, with the cap in place, the clients have rejected using NEST as it would necessitate linking with two solutions. Their preference was for a one solution provider (typically contract or Mastertrust) that would cater for all types of employee'.49 


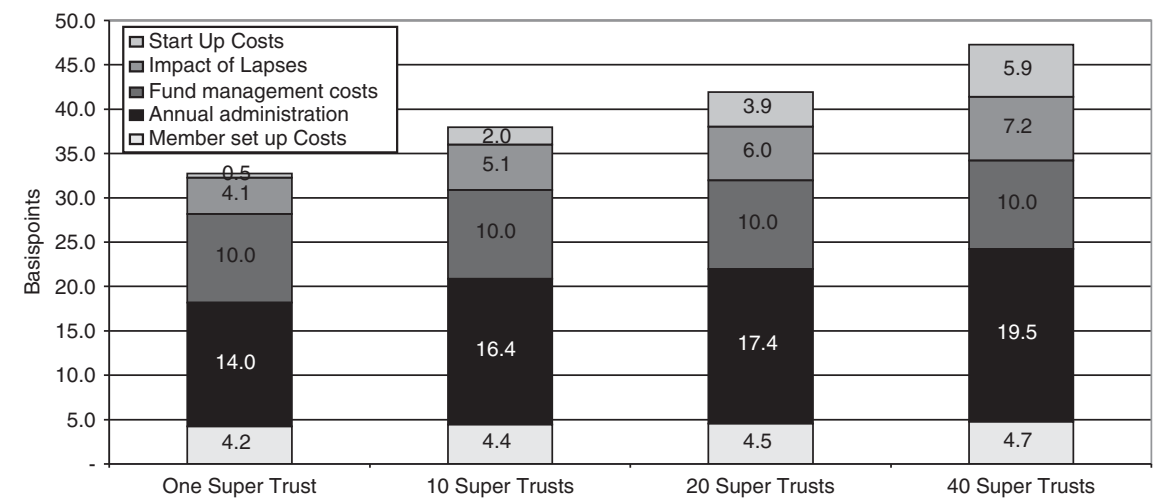

Figure 1: Breakdown of Super Trust management charges. Source: NAPF.

The Federation of Small Businesses told the DWP Select Committee that, if employers decided to avoid NEST as a result of the Cap, this could "expose many employees to the possibility that their money is deposited in funds that are not really suitable, thus losing a proportion of savings in higher fee charges', ${ }^{50}$

A succession of other witnesses also told the Select Committee that the contribution limit would create complexities for many employers. Consumer Focus highlighted that employers with both lower-paid and higher-earning senior staff could be put off using NEST as they would need a separate scheme for their higher-paid workers. ${ }^{51}$ Age UK agreed that the Cap might deter employers from using NEST, even for lower-paid employees who would benefit from its low charges and specially designed systems. ${ }^{52}$ The TUC was also concerned that the Cap would put an unnecessary burden on employers, who would have to offer more than one scheme for a workforce on varying salaries. ${ }^{53}$

These comments are consistent with a number of independent surveys, which said that very few surveyed firms would consider using NEST. See the article from Pensions Week in Appendix.

\section{Would lifting the ban on transfers-in allow NEST to drive private providers out of the market?}

Ban on transfers-in The ban on transfers-in freezes existing savings in the schemes in which they are currently located. It prevents competition from NEST for those savings. ${ }^{54}$ It means that an employer with a workforce that would be objectively better off in NEST may nonetheless be obliged to keep them in an inferior scheme. It would instead benefit the quality of competition and the results for low paid and medium earning workers if employers and employees could transfer existing savings. Owing to the scope for consolidation, private providers collectively could respond.

Example of the effect on NEST of the ban on transfers-in This anonymised example is provided by First Actuarial ${ }^{55}$ :

Two of our clients have old fashioned occupational DC plans which they want to upgrade. Many of the members earn little and contribute less, they are not attractive to the insurers of the scheme who have refused either to drop their charges or countenance taking on more employees when the companies stage auto-enrolment next year. We don't blame the insurers; they have no public service obligation to help these people.

The employers have suggested that perhaps they could transfer the member records and funds (using an actuarial certificate) to another occupational scheme and have asked whether we might approach NEST. They are aware that NEST has a public service obligation to accept 
auto-enrolled members - however commercially unattractive they may be.

No dice! NEST cannot accept transfers so it looks like the sponsors and their trustees are stuck between a rock and a hard place.

We thought help might be at hand from other master trusts. We have approached the new master trust providers who have entered the market in the last two years. But these providers will not take the small deferred pots on because they are uneconomic and would either put plan fees up or reduce the value of the mastertrust to its owners.

The situation continues to look bleak for the members and the employers. The employers are paying administration fees to manage a large number of 'small pots' and the members are continuing to pay high investment management fees.

Were NEST open to take this business and prepared to take both the small pots and the ongoing contributions then the members would see their annual management charges falling from an average of 1.3 per cent to 0.3 per cent. The company would be released from paying the account management charges (creating potential for improving its contribution structure going forward).

Even with the contribution charge currently in place, we reckon that were NEST open for this business, members would immediately benefit from better investment management and lower fees which would improve the pensions of these members within a year or so.

We cannot see how NEST is taking business away from other providers in cases such as the two mentioned above. We see the restrictions on NEST as detrimental to the interests of the many people in the UK with pension pots too small for the commercial market but too large to be ignored.

\section{Would lifting the restrictions lead to any over- compensation of state aid?}

To avoid over-compensation, compensation must '... not exceed what is necessary to cover all or part of the costs incurred in the discharge of public service obligations, taking into account the relevant receipts ...,56

Lifting the Transfer Ban cannot increase state aid at all. In so far as it leads to NEST covering its costs at an earlier date than expected, then, as the Commission has already found (paras 124 and 148), the system put in place by the UK government leads to an earlier repayment of the loan.

Lifting the Cap could possibly lead to a greater initial amount of subsidy if it leads to greater membership than originally expected. However, the original assumptions about take up are likely to be incorrect due to what have turned out to be two incorrect predictions: (i) that insurers and others would not seek to address much of the market for moderate earners and (ii) that there would be significant demand for a NEST that included only low and moderate earners. If lifting the Cap did lead to greater membership than expected and this allowed NEST to cover its costs earlier then it would, as above, lead to earlier repayment of the loan.

Aid should not be considered as per se overcompensation if it allows NEST to provide service to some higher earners. This is because as we point out above in section 'The Cap', demand is typically not segmented between low and medium earners on the one hand and higher earners on the other. Indeed, it was the same logic that led the Commission to agree in its original decision that NEST should be able to target profitable moderate earners. This was because the UK's detailed analysis showed that while there would be some increase in supply: 'many employers and workers would remain unprofitable to providers and be excluded from low cost saving' (para 22). ${ }^{57}$

\section{CONCERN THAT DWP HAVE NOT REVISITED THE ASSUMPTIONS BEHIND THEIR ECONOMIC MODELLING DESPITE MOUNTING EVIDENCE THAT THE CAP AND THE TRANSFER BAN UNDERMINE NEST'S ABILITY TO MEET ITS PSO}

The DWP has just published its base case for auto-enrolment. ${ }^{58}$ The section on the financing 
of NEST (p. 12 of the DWP Report) suggests that it has not yet revisited the assumptions behind its original modelling as to how NEST will meet its PSO. Market evolution since 2009 means that previous assumptions are unlikely to be valid. The DWP may be waiting for determinative evidence before conducting any revision so that it can say beyond reasonable doubt what the outcome of leaving the restrictions in place would be. If so, it is applying a standard of proof far stricter than that which is required. As I explained in section 'What standard of proof does the UK government need to meet as regards justifications for redesigning the PSO?' above, the standard of proof which the United Kingdom has to meet under EU State aid law requires it to show, in the light of the available evidence, why it is not manifestly incorrect to decide to define the public service obligation without the two restrictions. The serious practical problem with an approach based instead on proving beyond doubt that the restrictions must be lifted is that it would only be at that point when NEST has failed that one could then lift the restrictions. At such a point, it would of course be too late - as the contracts for most pension provision would already have been awarded. ${ }^{59}$

\section{MARKET DEVELOPMENTS SINCE 2010 HAVE UNDERLINED THE NEED FOR THE NEST RESTRICTIONS TO BE LIFTED}

There have been four market developments since NEST has been set up. None render NEST's public service obligation superfluous and they underline the need to lift the restrictions.

\section{Entry of providers to serve low and medium earners}

BC\&E and Now and some of the insurers now do offer pensions to moderate earners. However, they are under no obligation to serve all employers and employees. As commercial entities they will seek to avoid customers that will be unprofitable. In 2010, the new incoming UK government commissioned an independent review of automatic enrolment. The review found that it was still the case that private providers would not deliver a universal service. ${ }^{60}$

One of the consequences of these potential offers is that they will likely reduce the take-up of NEST among moderate earners, leaving NEST with a higher proportion of low earners. Private providers will try to target profitable members only. According to research conducted on behalf of DWP, private providers analyse a number of factors to avoid unprofitable members or raise price to deter their employers. The factors include: the size of the employer; the level of contributions expected; the proportion of the eligible workforce expected to become members; staff turnover; level of effort required by the provider in setting up and managing the scheme; age profile of the employees; industrial sector and geography of the employer; history of the financial adviser bringing in the employer in previously providing profitable business; and value of any transfers-in from previous schemes. ${ }^{61}$

\section{Cooperation agreements between NEST and other pension providers}

The reluctance of employers to deal with a company with a Cap has obliged NEST to try and team up with other private sector providers. ${ }^{62}$ This kind of joint activity will necessarily be more complex, less efficient and ultimately more costly for NEST's members.

\section{Continuing deterioration in pension saving in the United Kingdom due to lack of confidence in private pension providers}

The latest survey from the Office of National Statistics shows that, in 2011, only 33 per cent of private sector employees were a member of a workplace pension scheme. ${ }^{63}$ In evidence to the DWP Select Committee on Auto-enrolment, the department indicated that this figure represented a significant fall from 46 per cent in 1999-2000. ${ }^{64}$ A National Association of Pensions Fund survey found that 40 per cent of those intending to opt-out of auto-enrolment cite not trusting the pensions industry. It is the single largest reason for intending to opt-out. ${ }^{65}$ 
These findings are consistent with other surveys. ICM research found that 56 per cent of savers lack confidence in those who manage their investments. ${ }^{66}$ Which?, the consumer representation body in the United Kingdom, found that just 6 per cent of the public believe UK financial services are the most trustworthy custodian of a pension saver's money. Conversely, the most popular institution for pension saving was an independent government-sponsored body. ${ }^{67}$

A major report conducted by Professor Kay at the request of the UK Department of Business reported in July on the misalignment between the interests of savers and of financial intermediaries. He found, 'In the last five years, there has been a wide erosion of trust in financial intermediaries and in the financial system as a whole. This erosion is not a result of misplaced public perception, which can be addressed by a public relations campaign; it is based on observation of what has happened'. ${ }^{68}$ One of his major recommendations is that the relationship between savers and financial intermediaries must be based on fiduciary principles not simply contractual ones. NEST is already set up with trust-based governance. ${ }^{69}$ NEST could serve as an example on governance for those private providers that rely only on contractual relationships with customers.

\section{Government plans to accelerate the integration of the Basic State Pension and the State Second Pension into a single flat rate Pay As You Go state pension}

In the Commission's decision, it referred to NEST as a third pillar pension provider (see para 99). However, the complexity of the UK pension system means that private pension schemes have acted as second pillar as well as third pillar schemes. Going forward, auto-enrolment pensions will occupy the second pillar in the United Kingdom. One of the key distinctions between second and third pillar arrangements is that second pillar arrangements are based on the workplace and receive contributions from the employer and the employee. ${ }^{70}$
The Commission correctly identified the state second pension as within the UK's second pillar provision. However, occupational pensions are also second pillar pensions in the United Kingdom. Employees could contract out of the contributory state second pension if their employer offered an occupational pension that met certain quality criteria. Such occupational pensions could then substitute for the state second pension. In 2007, it was decided that defined contribution pension schemes (the kind of pension that will form the bulk of those purchased under auto-enrolment) had performed so inadequately that contracting out would no longer be permitted. The UK government is now intending to bring the state second pension to an end in 2015 and to merge it with the basic Pay As You Go state pension. Occupational pensions (including those into which people will be autoenrolled) will be the sole second pillar pensions available in the United Kingdom.

Saving with NEST is only available as an occupational pension. This is unlike third pillar pensions which are private pensions taken out to supplement what will be available from the basic PAYG state pension and the individual's occupational pension.

Persuading people to stay opted in to occupational pensions is essential for autoenrolment to achieve the ambition of median wage earners achieving a 50 per cent replacement of their earned salary in retirement. The proposed new combined flat rate basic pension would not reach such a level on its own. ${ }^{71}$ Indeed, many people will have to be persuaded to save more than the statutory minimum in auto-enrolled schemes in order to achieve a 50 per cent replacement rate. (The DWP Select Committee Report of 2012 calls on the government to 'conduct a review to examine (a) how to promote saving above the 8 per cent minimum; and (b) whether it should raise the statutory minimum above 8 per cent over the longer term'. ${ }^{72}$ )

\section{CONCLUSION}

To conclude, parliamentarians on the DWP Select Committee were right to call for the restrictions on NEST to be lifted as soon as 
possible (see the quote below). It is important to appreciate that this can be done without offending EU state aid rules if the UK government presents the arguments as to why the subsidy no longer qualifies as a state aid under the Altmark principles.

We understand the rationale behind the restrictions placed on NEST as part of the sensitive consensus agreed between the Government and the various stakeholders. However, we are very concerned that two restrictions will have unintended consequences: the Cap on contributions will add complexity for small and medium businesses, and the ban on transfers will be disruptive for both employers and employees who would like to transfer existing pension pots into NEST. We believe that these restrictions may prevent NEST from addressing the market failure that it was designed to resolve. If state aid rules allow, we therefore recommend that the Government removes the Cap on contributions and the ban on transfers as a matter of urgency. ${ }^{73}$

\section{ACKNOWLEDGEMENTS}

I am grateful to those in London and Brussels who kindly reviewed this article in depth.

\section{REFERENCES AND NOTES}

1 Case C-280/00, judgement of 24 July 2003.

2 Article 106(2) TFEU.

3 http://ec.europa.eu/eu_law/state_aids/comp-2009/n158-09.pdf.

4 Unattributed refs to paras in this note refer always to the Commission's NEST decision cited in Reference 3.

5 Section 27(8) http://www.legislation.gov.uk/uksi/2010/917/ article $/ 27 /$ made.

6 Note that the costs of membership for higher earners also take a number of years to be covered.

7 See section 'Does NEST have the cost base of a typical "well run" undertaking, given the PSO it has to deliver ?'.

8 Note that the role of the English courts in the State aid context is limited to upholding rights derived from Article 108 TFEU by granting remedies aimed at preventing breaches of a standstill obligation, or addressing the situation created by such a breach (for example, by ordering recovery of unlawful aid and/or awarding damages against the State). Although the English courts may be required to assess alleged state aid in order to fulfil that role, they do not, unlike the Commission, have jurisdiction to rule on the compatibility of State aid with the internal market.

9 Case T-289/03 BUPA and others v Commission [2008] ECR II-81 para 268.

10 Case T-289/03 BUPA and others $v$ Commission [2008] ECR II-81 paras 166-169 and 172; Case T 17/02 Fred Olsen [2005] ECR II -2031, para 261. Commission 'Communication from the Commission on the application of the European Union state aid rules to compensation granted for the provision of services of general economic interest', OJC 8/4 of 11.1.2012, para 48.

11 http://www.nestpensions.org.uk/schemeweb/NestWeb/ includes/public/docs/NEST-scheme-annual-report-accounts2011-2012,PDF.pdf.

12 Commission 'Communication from the Commission on the application of the European Union state aid rules to compensation granted for the provision of services of general economic interest', OJC 8/4 of 11.1.2012, para 70.

13 http://www.publications.parliament.uk/pa/cm201012/cmselect/ cmworpen/1494/149409.htm\#a24, Ev w47.

14 Workplace Retirement Income Commission (2011) p.33.

15 This characteristic of demand distinguishes the NEST case from the Dutch social housing decision by the Commission, where meeting demand from low earners was not conditional on meeting demand from higher earners (indeed the opposite would tend to be the case) http://ec.europa.eu/eu_law/ state_aids/comp-2009/n642-09-en.pdf.

16 Note that European competition law of which EU state aid law is a component is designed to protect competition not particular competitors. See for example with respect to exclusionary behaviour: "the Commission is mindful that what really matters is protecting an effective competitive process and that competitors who deliver less to consumers in terms of price, choice, quality and innovation will leave the market'. Commission 'Communication from the Commission Guidance on the Commission's enforcement priorities in applying Article 82 of the EC Treaty to abusive exclusionary conduct by dominant undertakings', OJC 45.7 of 24.2.2009.

17 European Commission 'Communication from the Commission on the application of the European Union state aid rules to compensation granted for the provision of services of general economic interest', OJC 8/4 of 11.1.2012, para 48.

18 European Commission 'Communication from the Commission on the application of the European Union state aid rules to compensation granted for the provision of services of general economic interest', OJC 8/4 of 11.1.2012, para 47.

19 NEST confirmed in evidence to the DWP Select Committee that it would experience some administrative difficulties and costs as a result of the cap on contributions. It explained that, in cases where the contribution cap is exceeded, there would be difficulties in identifying which contributions fell within and outside the cap, as well as in subsequent calculations relating to refunds and tax relief. It also noted that, if an individual has more than one employer, it would be costly to administer cases where the cap was breached.

20 Labour Party 'Pensions People Can Trust', p. 5.

21 http://research.dwp.gov.uk/asd/asd5/rports2009-2010/rrep591. pdf, p. 23.

22 ABI. (2012) 'Time to Act': Tackling our savings problem and building our future. p. 11.

23 http://www.nestpensions.org.uk/schemeweb/NestWeb/includes/ public/docs/understanding-reactions-to-volatility-and-loss,PDF.pdf.

24 http://research.dwp.gov.uk/asd/asd5/rports2009-2010/rrep591. pdfp. 4 .

25 http://www.autoenrolment.info/index.html.

26 SIPPs allow the saver to manage their investments directly and to invest in a much wider range of assets than just funds.

27 http://www.thersa.org/projects/enterprise/tomorrowsinvestors'Seeing through the British pension system', p. 9.

28 http://www.moneymarketing.co.uk/pensions/dwp-clarifies-autoenrolment-charges/1054599.article. 
29 Currency spreads are currently giving rise to litigation by pension funds in the United States: http://www.afponline.org/ pub/res/news/FX_Trading_Costs_Monitoring_is_Critical. htmlComment on practices in the United Kingdom: http:// www.pensionsweek.com/DB-Derisking/Trustees-could-savethousands-in-FX-fees.

30 http://www.scmprivate.com/content/file/pressreleases/pressrelease-scm-private-stock-lending-release-01-september-2011.pdf.

31 http://www.thisismoney.co.uk/money/pensions/article-2181679/ SAM-DUNN-Its-time-end-pension-exit-scam.htmland http:// www.pensions-institute.org/reports/caveatvenditor.pdf, p. 18.

32 The UK consumer representation body, Which?, calculates that the higher penalty charges, known as 'Active Member Discounts' can reduce people's pension pots by 25 per cent. See comment on an industry blog: http://langcatfinancial.co.uk/2011/10/ active-member-discounts-oops-we-did-it-again/.

33 http://www.abi.org.uk/Media/Releases/2012/03/Insurance_ industry_takes_big_steps_to_help_customers_make_the_most_of_ their_pension_savings.aspx.

34 A comprehensive critique of the ABI's recommendations was published by the National Association of Pension Funds: http:// www.napf.co.uk/PolicyandResearch/DocumentLibrary/ / media/Policy/Documents/0214_Consumers_in_the_retirement_ income_market_-_NAPF_response_to_the_ABI\%20consultation. ashx.

35 ABI 'UK Insurance -Key Facts' (September 2011), p. 19.

36 Steve Bridger, head of group risk at Aviva UK Health, said: 'Offering one times salary life cover can cost only 0.1 per cent of payroll, and life cover is not complex and doesn't require a long-winded sales process. We are looking at a number of options to use existing strong relationships with clients to cross-sell on the life side, using the same research and overall intelligence in terms of relationship management as our pensions colleagues. The composite nature of our business can be an advantage as it enables us to construct a proposition that may have a minimal amount of life cover that can be attached to a pension. With income protection, on the other hand, there are fewer opportunities for such cross-selling' http://www. moneymarketing.co.uk/channels/corporate-adviser/group-risk/ a-double-edged-sword/1032368.article.

37 Workplace Retirement Income Commission (2010), p. 33.

38 The Pensions Regulator, DC Trust 2010, The Purple Book, 2010.

39 NAPF. (2009) DC default funds: today and tomorrow, p. 7.

40 https://www.pensionspolicyinstitute.org.uk/uploaded documents/2012/20120627_PPI_MetLife_The_changing_ landscape_of_pension_schemes_in_the_private_sector.pdf, p. 7 .

41 http://www.abi.org.uk/Facts_and_Figures/Facts_Figures.aspxsee the Data Bulletin.

42 https://www.autoenrol.capitahartshead.co.uk/PDF/press/ Master\%20Trusts\%20-\%20Gaining\%20Popularity.pdf.

43 http://www.pensionsworld.co.uk/pw/article/dc-focus-backin-control-12319071.

44 DWP research published in September 2012 found that two-thirds of employers did not understand the most basic element of the charges that would be applied to their employees and comprehension declined even further for more esoteric forms of charging http://research.dwp.gov.uk/asd/asd5/report_ abstracts/rr_abstracts/rra_804.asp.

45 See section 'Straight-forward product'.

$46 \mathrm{http} / /$ www.thersa.org/projects/enterprise/tomorrowsinvestors'Seeing through the British pension system', p. 9.
47 http://www.ft.com/cms/s/0/5d850840-df08-11e1-97ea00144feab49a.html\#axzz24e4LHDbi.

48 The Pensions Commission: A New Settlement for the Twenty First Century: The Second Report of the Pensions Commission (2005); NAPF, Putting Members First (2012), p. 13.

49 Quote kindly provided by Mark Jaffray to the author of this article.

50 http://www.publications.parliament.uk/pa/cm201012/cmselect/ cmworpen/1494/149409.htm\#a24Ev 161.

51 Ibid, Ev w8.

52 Ibid, Ev w27.

53 Ev 124

54 There is also a ban on transfers out of NEST. This is a corollary of the ban on transfers in. Both should be removed.

55 Source: Henry Tapper, Director, First Actuarial.

56 Commission "Communication from the Commission on the application of the European Union state aid rules to compensation granted for the provision of services of general economic interest', OJC 8/4 of 11.1.2012, para 60.

57 Para 22 of the Commission decision in full: 'The UK has undertaken a detailed analysis of whether the existing pensions market would expand sufficiently following the introduction of automatic enrolment and a minimum employer contribution to cover all employers and their workers affected by the new employer duty. It concluded that although the current market would to some degree expand, many employers and workers would remain unprofitable to providers and be excluded from low cost saving. The UK concluded therefore that a different form of provision - a large scale multi-employer occupational pension scheme - was required in order to harness economies of scale and deliver widespread coverage at a low average cost'.

58 http://research.dwp.gov.uk/asd/asd5/rports2011-2012/rrep803. pdf.

59 As this article went to press DWP published a call-for-evidence with respect to the NEST restrictions which is intended to gather information for a re-appraisal: http://www.dwp.gov.uk/ docs/nest-automatic-enrolment-call-for-evidence.pdf.

60 http://www.dwp.gov.uk/docs/cp-oct10-full-document.pdf, p. 67.

61 http://research.dwp.gov.uk/asd/asd5/rports2009-2010/rrep591. pdf, p. 23

62 http://www.ifaonline.co.uk/ifaonline/news/2199065/scottishlife-unveils-nest-tieup.

63 ONS. (2012) 2011 Annual Survey of Hours and Earnings: Summary of Pension Results, p. 1.

64 http://www.publications.parliament.uk/pa/cm201012/cmselect/ cmworpen/1494/149405.htm\#a6, para 14.

65 NAPF Spring 2012 workplace pensions survey: http://www .napf.co.uk/PolicyandResearch/ /media/Policy/Documents/ 0220_NAPF_workplace_pensions_survey_-_March_2012 .ashx, p. 7.

66 SCM Private LLP. (2012) Promoting trust and transparency in the UK Investment Industry. , p. 13. Independent ICM Research Poll of 2029 adults across the UK in December 2011.

67 Which? Consultation response to the Work and Pensions Committee, October 2011, p. 5.

68 Report of the Kay Review of UK Equity Markets and Longterm Decision Making. (2012) http://www.bis.gov.uk/kayreview.

69 While regulation could also attempt to achieve the same ends, a structural solution like NEST is likely to encourage a market response by competitors as a reaction to the competitive process. In general, competition authorities, including the European Commission, prefer effective structural solutions over 
behavioural ones; see for example, Commission 'Commission Notice on remedies acceptable under Council Regulation EEC nNo.139/2004 and under Council regulation EC No. 802/2004', OJC 267/5 of 22.10.2008, paras 15-18.

70 Z A Research Report No. 42 Pension Systems in the EU Contingent Liabilities and Assets in the Public and Private Sector. Based on a study conducted for the European Parliament under contract IP/A/EMPL/FWC/2008-002/C1/SC5 http:// www.iza.org/en/webcontent/publications/reports/report_pdfs/ iza_report_42.pdf, p. 26.

71 The new flat rate state pension would provide income of E7280 per year.

72 DWP Select Committee, p. 17.

73 http://www.publications.parliament.uk/pa/cm201213/cmselect/ cmworpen/154/15404.htm, para 175.

\section{APPENDIX}

\section{Pensions week}

Further gloom for Nest

By David Rowley|01 April 2012|

Further evidence of the low take-up of the National Employment Savings Trust (Nest) has been confirmed by feedback from payroll providers and consultants.

Research by Towers Watson has already revealed only 4 per cent of its clients are planning to use Nest as a core pension vehicle for autoenrolment, with two-thirds committed to using existing schemes.

Feedback from consultancy firm Buck Consultants shows it is struggling among medium-sized employers too

And leading payroll provider Ceridian has confirmed only one of its 30 clients with staging dates for auto-enrolment between now and July 2013 will be using Nest.

The provider said it expected more of its small to medium-sized enterprise (SME) clients to use Nest, but there are growing fears the lack of volume provided by big employers will make it harder for Nest to pay back its start-up loans to the government.

Where it is being used by large employers it will either be for low-paid transient employees or as a nursery scheme for new employees.

Feedback from consultancy firm Buck Consultants shows it is struggling among medium-sized employers too.

Only one of its 120 clients plans to use Nest.

Similarly, payroll provider Sage says only 9 per cent of its SME clients have decided to use Nest. These figures come with the caveat that around two-thirds of Sage's SME clients have decided on a definite plan for auto-enrolment.

Further uncertainty over take-up of Nest comes from the deals Friends Life and Standard Life worked out with it on splitting segments of the workforce, so that the providers retain the higher-paid, long-term staff and Nest administers the remainder.

The Department for Work and Pensions is considering removing restraints on the level of contributions Nest can receive, and its ban on receiving transfers in, to help it compete in the auto-enrolment market. 